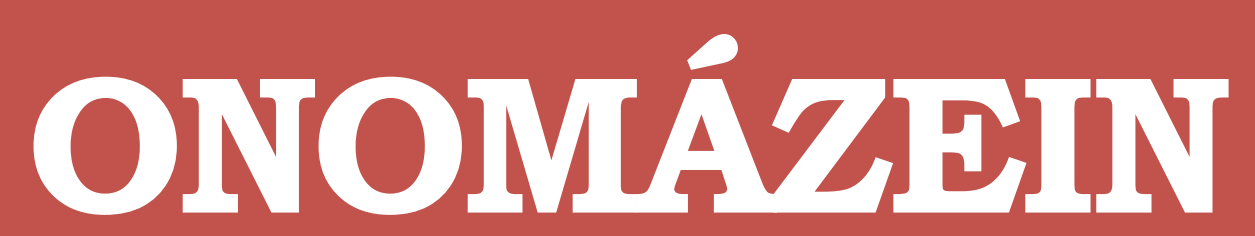

Journal of linguistics, philology and translation
PONTIFICIA UNIVERSIDAD

\title{
From the concepts of meaning and reference to the concept of prototypicality
}

\author{
Carlos Assunção \\ UTAD \\ Portugal

\section{Carla Araújo} \\ IPB \\ Portugal

\section{Gonçalo Fernandes} \\ UTAD \\ Portugal
}

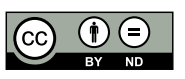

Carlos Assunção: UTAD, Portugal. | E-mail: carlos.costa.assuncao@gmail.com Carla Araújo: IPB, Portugal.

Gonçalo Fernandes: UTAD, Portugal. Orcid:0000-0001-5312-6385. | E-mail: gf@utad.pt 


\section{Abstract}

Meaning is a uniquely human phenomenon. In linguistics, this subject matter is especially complex, considering the multiplicity of theoretical approaches and the variety of disciplinary fields that address the issue. A similar concern applies to the concept of reference, because, although most linguists today agree that meaning and reference form two different realities, the discussion about the relation between these two terms has not yet been fully examined.

Cognitive Linguistics has made a great contribution to this discussion by recognizing that we cannot present the postulate of the existence of a level of meaning that belongs only to language and is distinct from the level at which the meaning of linguistic forms is associated with the knowledge of the world.

The objective of this work is to show that, with Cognitive Linguistics, the ideas of meaning and reference are re-equated and have gained strength in the scope of linguistic studies reinforced by the concept of prototype. For such purpose this text describes the way these concepts have evolved based on their theorisation, paying particular attention to cognitive semantics, but not intending to make an exhaustive theoretical-methodological analysis of them.

Keywords: historiography; lexicon; semantics; meaning; reference; prototype. 


\section{Introdution}

The trivial events of daily life are filled with information that we interpret without really noticing and that govern our ways of (re)acting and condition our behavior. We permanently search for meaning (Abrantes, 2011).

All signs signify, that is, produce, a given meaning. By nature and by definition, all signs have meaning, for meaning is a concept or mental representation that can be understood from a personal and cultural perspective.

Meaning is the means by which human beings come to express ideas, concepts and beliefs to other people, using words, gestures and actions. These means are known as signs or signals, generally speaking

Since this is relevant, meaning has naturally emerged as a subject of scientific interest. Defining meaning is one of the greatest problems of semiotics, and it represents the field of semantics. This linguistic discipline aims to describe the relationship established between expression and the ideas or concepts evoked in the mind when someone utters a word or makes a gesture. Semantics also includes the study of the relationships between meanings. The field of study of semantics of a word is also called lexical semantics (Abrantes, 2011).

The debate on reference has been of growing interest. Conceptions of reference differ, according to the theoretical model adopted. The formation of reference and the relationship it establishes with meaning, its role in discourse and language and the knowledge of the structure that enables its formation and interpretation are some of the recurring themes that concern linguists and experts of semantics, particularly. Just like reference, polysemy is also a current topic of research, revealing limits of the traditional concepts of meaning.

Polysemy, which was of particular interest to lexicology and lexical semantics, has expanded to other fields, such as computational linguistics. In this context, the treatment of ambiguity inherent in polysemous words is of utmost importance. The reduction of ambiguity arising from identical lexical units, from a formal point of view, represents one of the biggest challenges for computational linguistics.

In order to investigate the lexical-semantic properties intrinsic to the complexity of the lexicon, Lexical Semantics studies the various features that reveal the distinct and complementary aspects of the lexicon.

These investigations have, in turn, been the object of study of multiple domains by Cognitive Sciences and by Automatic Processing of Natural Languages.

For Cognitive Linguistics, cognition is determined by our own bodily experience and by the individual and collective experience, but it is also the paradigmatic axis, equated in its etymolog- 
ical sense of example, model and pattern, synonymous with prototype, which advocates that interpretation and acquisition of new experiences take place within already-existing concepts and categories, enabling them to function as interpretive models, as paradigms or prototypes.

The concepts of meaning, reference and prototypicality have already been the subject of several studies. Researchers such as Langacker (1987, 1990, 1991, 1999, 2008), Talmy (1983, 1988a, 1988b, 2000), Lakoff and associates (Lakoff \& Johnson, 1980, 1999; Lakoff, 1987; Johnson, 1987; Lakoff \&Turner, 1989), Feltes (2007), Smith \& Medin (1981; Medin \& Smith, 1984), Coleman \& Kay (1981), Geeraerts (1985, 1988a,1988b, 1989, 1995, 1997), Wierzbicka (1985), Kleiber (1990), Taylor (1995), Frege (1973), Saussure (1978), Teixeira (2001), Rastier, Cavazza \& Abeillé (1994), Fauconnier \& Turner (2002), Franckel (2006), Traugott \& Dasher (2002), Wittgenstein (1979), Rosch (1978), Rodrigues (2012), Silva (2006), Taylor (1995), Eco (2004), Wierzbicka (1985), Abrantes (2011), Mesquita (1997), among others, have developed studies in the field of that concepts, as we will outline below.

We focus on these issues in this study.

\section{Concepts of meaning and reference}

The discussion of the relationship between sense and reference is far from over. The interest in this phenomenon is as old as philosophy. In Classical Antiquity, Plato, in Cratylus, and Aristotle, in Poetics, in particular, reflected on the nature of the relationship established between the object, its mental representation and its name.

Analyzing the referential function of the word, in Plato's Cratylus, and its subordination to the thing being named that immediately emerges, Mesquita believes that:

Generally speaking, and not thinking specifically of the text under study, it seems clear that the main consequence is the immediate affiliation of words with the things they have named, that is, the primacy of denotation over connotation or the referent over the meaning of the word; if

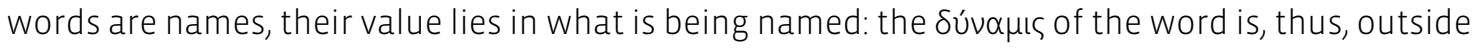
itself. Then, language is not autonomous with respect to the reality that it appoints, but, on the contrary, it is only fulfilled in the relationship that is established in the process of nomination. The heteronomy of the word is, in this light, the first consequence of its assimilation to the name.

An intimate and irreducible relationship is, therefore, established between words and things, a relationship that is structured on the basis of the sign of nomination, that is, on the basis of the sign of unidirectional reference by which the former is just expected to indicate the latter in the most transparent way possible. The heteronomy of the name is, thus, the trait of the fundamental imbalance that constitutes such a relation: the words are emptied every time they try to fulfill their role; the presence of the thing is the counterpart of the radical absence that forms the nature of the word. 
To name is not simply to replace things with words: it is much more to make the thing replace itself subtly with that empty sound that forms the name (Mesquita, 1997: 3; our translation).

The fact that the intimate relationship between words and things is extremely intricate allows language to be reduced to the game developed between them both. In this sense, Ianguage can no longer be viewed simply in terms of its distinguishing feature of words, having to be perceived only within that relationship. The relationship through which words refer to and embrace the things being named is the essence of language.

Within linguistics, the importance of meaning and reference revolves around the ideas of the German Friedrich Ludwig Gottlob Frege, as seen in his Über Sinn und Bedeutung (1892).

Frege's article about sense and reference, published in 1892, is of primordial importance for logic and the philosophy of the twentieth century, considered one of the main sources of modern semantics. In it, Frege distinguishes between the referential and the attributive dimensions of the signs, laying the bases for the descriptive distinction between sense and reference, essential concepts for modern semantics and pragmatics. The classic example Frege presents to clarify the distinction between sense and reference is apparent in the expressions "morning star" and "evening star". The expression "morning star" means it is the last star to be absent from the firmament at dawn, and "evening star" denotes the first star to appear in the sky after sunset. We deal with linguistic expressions with different meanings, although we know that their referent is the same, that is, the planet Venus. Starting with the matter of equality, Frege argues that equality is a relation of signs. He claims that:

(...) $\mathrm{a}=\mathrm{a}$ and $\mathrm{a}=\mathrm{b}$ are obviously statements of different epistemic value: $\mathrm{a}=\mathrm{a}$ holds a valid a priori and, according to Kant, is to be labelled analytic, while statements of the form a = b often contain very valuable extensions of our knowledge and are not always justifiable a priori. The discovery that the rising sun is not new every morning, but always the same, was one of the most fertile astronomical discoveries. Even today the re-identification of a small planet or a comet is not always a matter of course. Now, if we were to regard equality as a relation between that which the names 'a' and ' $b$ ' refer to, it would seem that $a=b$ could not differ from $a=a$, provided $a=b$ is true. A relation would thereby be expressed of a thing to itself, and indeed one in which each thing stands to itself but to no other thing. What we apparently want to state by $a=b$ is that the signs or names ' $a$ ' and ' $b$ ' designate the same thing, so that those signs themselves would be under discussion; a relation between them would be asserted. But this relation would hold between the names or signs only insofar as they named or designated something. It would be mediated by the connection of each of the two signs with the same designated thing. This connection is arbitrary (Frege, 1973: 49; our trans/ation).

Not always is it possible to make a sense match a reference. The expression "the body furthest away from the Earth" surely has a sense, but it is very doubtful whether this expression refers to any object. 
Certainly, in a perfect system of signs, a determinate sense should correspond to each expression; but popular languages often fail to fulfil this demand, and one has to be content if at least in the same context the same word always has the same sense. Perhaps one might concede that a grammatically correctly formed expression that stands in for a proper name always has a sense. But that does not settle whether there is also a reference that corresponds to the sense. The words 'the celestial body furthest away from the Earth' do have a sense; but it is very doubtful whether they also have a reference. The expression 'the least convergent series' has a sense; but one proves that it has no reference, because for each convergent series one can find a less convergent one that is still convergent. Thus, grasping a sense does not yet guarantee having a reference (Frege, 1973: 52-53; our translation).

On one hand, Frege advocates that meaning is not a subjective representation; that is, meaning is objective. On the other hand, the representation that a speaker has of a given object is only that person's representation, and it differs from the representation that other speakers have of the same object:

A painter, a horseman, a zoologist will associate very different ideas with the name "Bucephalus". This constitutes an essential distinction between the representation and the sign's sense, which may be the common property of many and therefore it is not a part of a mode of the individual mind; for one can hardly deny that humanity has a common store of thoughts which is transmitted from one generation to another. Thus, while there are no misgivings about speaking of the sense without further qualification, one must, strictly speaking, add, in the case of the representation, whom it belongs to and at what time. One might say: just as one person connects this representation, and another that representation, with the same word, similarly one may associate this sense with it, and another that sense. But, in that case, the difference does not consist merely in the kind of association. This is no obstacle to both grasping the same sense; while they cannot have the same idea.

Si duo idem faciunt, no est idem [= if two do the same, it is not the same]. If two people have a representation of the same, then each still has their own representation. Even though it is on occasion possible to discover differences between the ideas, or even feelings, of different people, a precise comparison is not possible because we can't have these ideas together in the same consciousness (Frege, 1973: 54-55; our translation).

The Fregean distinction between sense and reference has dominated much of the modern development around semantics, leading to today's most current distinction between intension and extension, which we discuss later with the theory of the prototype.

Saussure, the maximum representative of the dual conception of sign, abstracts from reference, considering it an ontological, rather than semiotic, issue. Saussure argues that "the linguistic sign unites not a thing and a name, but a concept and an acoustic image" (Saussure, 1978: 122). For Saussure, what is really linguistic has to be immaterial. Therefore, everything that encompasses any aspect of reality whatsoever does not fit in the field of Linguistics. According to Teixeira (2001): 
Saussure's mistake is, in our view, not in his ignorance of the referent-meaning relationship but in his will to develop Linguistics, putting this first relation aside and exclusively privileging the meaning-significant relationship, untying the former from all the ties that necessarily link it to reality.

It is therefore not fair to say that, for Saussure, the relationship between referent and meaning has nothing to do with language; it is just not related to the Linguistics that Saussure wants to develop. The fact is that Saussure accepts the importance of everything that pre-exists, produces or modifies meaning: he does not consider it as having to be part of his Linguistics, though (Teixeira, 2001: 82; our translation)

Actually, the Saussurean thought led to the fact that, in structuralism, language was perceived as having para-material value; thus, the object of Linguistics was no other than simple formal reality.

Out of this pure network of forms, of "values", was everything that, although indirectly linked to language, was designated as "extra-linguistic". By separating form and substance, either within "expression" or within "content", Hjelmslev refines the Saussurean duality, leaving the study of purely formal relations, independent of the tangible features that support them, for his Glossematics. Linguistics is, thus, not only a para-material science, but also an anti-material one.

Some more than others, all structuralists perceived the linguistic phenomenon as something that only took place beyond sensible reality, either of the user of the language or of the world that this language embraces and refers to. And because the dichotomies set a trend, the linguistic phenomenon was perfectly distinguished (or wanted to be distinguished) from the extra-linguistic one.

By placing a man, with all his cognoscitive activities, in-between the reality that seeks to express and the language used precisely to express it, cognitive conceptions have broken the dual equilibrium that was heretofore unquestioned (Teixeira, 2001: 84; our trans/ation).

Given the relevance of structural semantics and cognitive semantics in debates focusing on the lexical meaning, let us ponder issues of reference in light of these two paradigms.

From the standpoint of classical structural semantics, creator of synchronic lexicology and lexical semantics, the reference is seen as a kind of obstacle to the emergence of a truly linguistic meaning. This view derives from the goal of moving away from the philosophy of language and psychology, granting a particularly linguistic character to semantics.

During the 1980s, the time was ripe for bringing together linguistics, computer science and cognitive psychology, establishing what we currently know as cognitive sciences. It is in this context that the conceptions of meaning and reference, which have been the focus of scholars for some thousands of years, are reproblematised, thus reopening the debate on meaning and reference.

Rastier, Cavazza and Abeillé (1994) argue that

As far as reference is concerned, we cannot take into consideration the direct reference that links expressions and objects without any mediation, because in fact it denies the existence of a seman- 
tic level proper to languages. [...] Differential semantics deals primarily with reference by describing the semantic constraints on representations (Rastier et al., 1994: 39; our trans/ation).

Consequently, they assert that "la question de la référence devient alors celle des impressions référentielles. Son étude requiert une collaboration de la sémantique et de la psychologie [the issue of reference then becomes that of referential impressions. Its study requires collaboration between semantics and psychology]" (Rastier et al., 1994: 39). As a result, referential impressions are associated with mental representations and, thus, with psychology, being separated from the field of linguistic semantics. The development of studies concerning this theory enabled the reformulation of some of its assumptions, giving rise to Fauconnier and Turner's Theory of Conceptual Integration (2002), which focuses particularly on studies concerning forms and meanings. In this theory, the authors postulate that there is no dichotomy between form and meaning, but rather an indissoluble link between them. Based on this postulate, discursive processing is understood as the instantiation of mental operations that echo in the materiality of the text, whether oral or written, and that leads us to consider not only the importance of the word, but also the context of its production and other cognitively processed information in discursive processing

It is in this light that Franckel (2006) highlights the relationship of interaction between a particular linguistic unit and its context ("large contexte" [broad context] or "situation" [situation]):

The broad context plays on a larger scale: it goes beyond the scope of an utterance and falls within what we can call the framework, the background, or even the history in which this utterance is inscribed, and its interpretation becomes clearer. At this scale, the modification of a term in this environment no longer acts directly on the meaning of a word or sequence, and the variations of meaning are no longer of a discontinuous order. Thus, we see that the boundary between situation and context fade away, the latter resembling situation, even if it is of a textual order. What happens is simply that situation - being relevant to the interpretation of an utterance - is, or is not, made explicit by a verbal form. But what we are always referring to is an interpretive environment (Franckel, 2006: 2; our translation).

Reality exists beyond human beings, that is, reality cannot be changed, even if the way we perceive it can vary. In other words, individuals apprehend reality according to their perception of the world or their worldviews. Therefore, the meanings of the linguistic forms are not mere reflections of the properties of the phenomenon; instead, they reflect our conceptualisation of the phenomenon and, in that sense, they are subjective.

\section{Brief synopsis and contribution of Cognitive Linguistics to the concept of meaning}

In the context of Cognitive Linguistics, meaning is understood as conceptualisation, conceptual content, mental fact, thus configuring cognitive or conceptual semantics: "Meaning is a 
mental phenomenon that must eventually be described with reference to cognitive processing” (Langacker, 1987: 97).

According to Langacker (1987: 6; 2008), meaning must be understood as conceptualisation, that is, as a mental experience, well established or new, abstract or sensory-motor and emotional, encompassing the apprehension of the physical, social and linguistic context. In this way, meaning results from a cognitive process and a neurological activity of the human mind, physically embodied and socially and culturally contextualised.

According to Talmy (2000: 4), "research in cognitive semantics is research on conceptual content and its organisation in language and, consequently, on the nature of content and conceptual organisation in general” (our translation).

Talmy's viewpoint is that qualitative mental phenomena, as they exist in awareness, are the main object of study of Cognitive Semantics. This scholar argues that Cognitive Semantics studies the formal properties of language from a conceptual perspective, on the one hand, a perspective that is concerned with "the patterns in which and processes by which conceptual content is organised in language" (Talmy, 2000: 2), and, on the other hand, it aims to associate its studies with the cognitive structures of the psychological approach, which includes the analysis of semantic memory, the associativity of concepts, the structure of categories, inference generation and contextual knowledge.

To conceive meaning as conceptualisation implies being able to understand that conceptualisation takes place through certain processes and certain semantic structures, of which polysemy is an example. These mechanisms of conceptualisation are shared by human beings.

Within the most representative views of conceptual focus as the main function of language and the perspectivism inherent to the nature of meaning, included in Cognitive Semantics, three complementary views are presented, although they are variations of the same facts, in some respects: Langacker's conventional imagery (1987, 1990, 1991, 1999, 2008), Talmy's imaging systems (1983, 1988a, 2000) and the studies on figurative language, as developed by Lakoff and his colleagues (Lakoff \& Johnson, 1980, 1999; Lakoff, 1987; Johnson, 1987; Lakoff \&Turner, 1989).

Langacker (1987, 1991, 1999) and Talmy (2000) argue that this capacity for conceptual perspectivism is the main function of grammar. Under the umbrella of conventional imagery, Langacker (1987) distinguishes three types of conceptual perspectives, understood as focal adjustments (Langacker, 1987: 117): Selection¹, Perspective² and Abstraction³.

1 For further reading, cf. Langacker (1987: 117-120).

2 For further reading, cf. Langacker (1987: 120-132).

3 For further reading, cf. Langacker (1987: 132-137). 
The images employed to structure conceived situations vary with respect to a number of parameters. I will refer to such variation as focal adjustments ${ }^{4}$ (permitting myself a visual metaphor). The discussion is organized under three broad headings. Focal adjustments of selection determine which facets of a scene are being dealt with. Perspective relates to the position from which a scene is viewed, with consequences for the relative prominence of its participants. Finally, abstraction pertains to the level of specificity at which a situation is portrayed (Langacker, 1987: 117).

Langacker $(2007,2008)$ replaces this classification, which was initially divided into three, with another composed of four concepts: Specificity, Prominence, Perspective and Dynamicity. Differentiating four imaging systems, Talmy (1988a, 2000) presents the concepts that follow: Schematisation (or Configurational Structure), Perspective, Distribution of Attention and Force Dynamics.

The shift from an objective perspective to a more subjective perspective represented subjectification (Langacker, 1999; Traugott \& Dasher, 2002), that is, subjectification can be conceived of as a mechanism that weakens an objectively-construed entity, overemphasising the subjective perspective of the speaker/conceptualizer.

The Perspective category is the conceptual basis for the construal relationship. According to Langacker's glossary (1987: 487-488), the construal relationship is "the relationship between a speaker (or hearer) and a situation that he conceptualizes and portrays, involving focal adjustments and imagery."

In the field of Cognitive Linguistics, semantic-conceptual matters are privileged.

Cognitive Linguistics regards language as an integral part of cognition and in interaction with other cognitive systems (perception, attention, memory, reasoning, etc.). In this sense, it is receptive to interdisciplinarity with other cognitive sciences and, thus, it not only brings together useful data from these sciences in the theorization and description of language, but it also offers its contribution to the study of human cognition.

By accepting the link between categorization and the extra-linguistic and encyclopedic dimension in the construction of meaning, then cognitive semantics combine the referential paradigm.

The philosophical and epistemological orientation of Cognitive Linguistics is characterized by the importance that it assigns to semantics in the linguistic analysis and in its attempt to prove the encyclopedic and perspectival or perspectivizing nature of linguistic meaning

\footnotetext{
4 Author's emphasis.

5 LANGACKer, Ronald W. (1990): "Subjectification”, Cognitive Linguistics I (1), 5-38.
} 
(Geeraerts, 1995: 113). This supremacy of semantics results from the cognitive perspective itself, a proponent of the assumption that the primary function of language is categorization. In this context, meaning is the main linguistic phenomenon, to such an extent that the encyclopedic nature of signification stems from the categorizing function of language; that is, if we use language to categorize the world, then linguistic signification cannot be detached from the knowledge of that world. Due to its categorizing function, language does not objectively portray reality, but it postulates a structure in the world. The perspectival and perspectivizing nature of linguistic signification stems from this postulate.

Within cognitive semantics, we now look at the prototype theory.

\section{Prototype concept advocated by Cognitive Linguistics}

The prototype theory opposes the classical theory or the logic of categorization. The classical conception of categorization is a theory with a long-standing tradition, and modern linguistics, both structuralist and generative, also follow it. It is based on the following assumptions: the categories have clear and precise boundaries; that is, either an item belongs to a given category or does not; within this category, the various items are equal; that is, there is no hierarchy of members; the categories and their items are known as evidencing a limited number of sufficient and necessary semantic features; the items can be used for tests: if they have the necessary and sufficient semantic features, they are included in the category, otherwise, they are not part of the category. The shortcomings and constraints revealed by this theory led to a new approach that resulted from developments in applied psychology, the prototype theory.

Cognitive Linguistics argues that the various members or properties of a category usually show different degrees of salience; that is, some are prototypical, and some others are peripheral, clustering into groups mainly according to partial similarities, which Wittgenstein named "family resemblances":

I can think of no better expression to characterize these similarities than "family resemblances"; for this is how the various similarities between members of a family overlap and criss-cross: build, features, color of the eyes, gait, temperament, etc., etc. - and I shall say: games form a family (Wittgenstein, 1979: 39; our translation).

Just as, in a family, we notice that there are some members that share traits with other relatives and other features with other different members, so do the categories organize themselves in this way. There are traits or characteristics that are typical of a category; that is, some members share some of these traits, and some others share other characteristics. However, there are no traits or characteristics that all of them share. Wittgenstein raised the following question, drawing our attention to the game category: 
Consider, for example, the activities that we call "games". I mean board-games, card-games, ballgames, Olympic games, etc. What is common to them all? Don't say: "They must have something in common, or they would not be called 'games"' - but look and see whether there is anything common to all. For if you look at them, you will not see something that is common to all, but similarities, affinities, and a whole series of them at that. As I said: don't think but look! (Wittgenstein, 1979: 38; our translation).

Within this framework, Wittgenstein criticizes the definition of meaning as something fixed, complete and unique, and, therefore, the question "what is the meaning of a word?" is an erroneous one, due to the fact that it expects a unique and absolute answer. According to this Austrian philosopher, it is not necessary to know the meaning of a word in its fullest sense; any attempt in this direction would lead us to a wrong conception of it, since meaning consists of a range of uses we make of words, so much so that knowing one use of a word is recognizing only one side of its meaning. These are concepts that are agglomerated by a series of traits that, on the one hand, are not fully evoked by a user or, on the other hand, are shared by all the other users. This is the principle that leads us to prototype theory.

The conception of categorization, known as prototype theory, was pioneered through the psycholinguistic research of Eleanor Rosch (1978) and her followers on the categorization of colors, birds, fruit and other types of entities. Afterwards, it was developed in the field of Psychology, with the purpose of devising formal models for human conceptual memory, something that was also of interest to Artificial Intelligence and to the domain of Linguistics, particularly to Lexical Semantics, with the label Prototype Semantics.

In the seventies of the twentieth century, Eleanor Rosch presented an approach to prototype theory that establishes a certain item as the starting point, a nucleus, for each category. This conception differs from that expressed by Wittgenstein (1979), who, instead of analyzing prototypical centrality, analyzes items that have family resemblances, but it does not mean that one item is a more privileged prototype than another within a category.

After investigating the wide variety of activities for which we use the term "game", Wittgenstein advocates that the necessary conditions for its definition are not created, because there are no characteristics that must, jointly, be part of all events under the same name. In light of the above, Rodrigues (2012: 131-132), analyzing the "necessary and sufficient conditions in categorisation", according to the Jackendoffian model, states that these concepts are:

(...) "clusters". In other words, they are concepts that are made of a series of traits that are neither fully part of an object nor part of all the individuals. Nevertheless, these objects are attached to the same concept, bearing in mind conditions that are neither necessary nor rigidly grouped. Prototype theory lays its foundations in this conception.

Regarding the Jackendoffian model $(2002,356)$, the prototype is seen as an instantiation that satisfies the maximum conditions of the "cluster" concept. It is not the concept that is defined as repre- 
sentation of the prototypical instantiation. For example, a sparrow (instantiation) is the prototype of the bird "cluster" concept, because it satisfies the conditions of the concept to its full potential. It is not the concept of bird that is a conceptual scheme of sparrow (prototypical instantiation) (Rodrigues, 2012: 131-132; our translation).

Discussing the foundational principles of Cognitive Linguistics, Silva argues that:

all language is, after all, about meaning. And the linguistic meaning is flexible (adaptable to the inevitable changes of the world), not neutral (it does not mirror, but constructs, the world), encyclopedic (closely associated with world knowledge) and based on experience and use (individual and collective experience and experience of the current use of language) (Silva, 2006: 297; our translation)

In this context, the cognitive ability of categorization and the way we identify, classify, name and organize the enormous variety of the world that surrounds us prove that we categorize, most of the time, "not in the form of individually necessary, and jointly sufficient, conditions and, therefore, not according to the so-called classical theories, but on the basis of prototypes" (Silva, 2006: 298)

Actually, as Silva concludes:

If categorization was to take place on the basis of common properties and in accordance with the Aristotelian principle of the "excluded third", by which an entity either exhibits or does not exhibit a given characteristic, then the infinity and diversity of things, processes, relationships, etc., that form our world would require not only monosemic categories, or at least simpler ones, but also an infinitely greater number of categories, which would certainly compromise the learning and usage of a language. The naturalness and frequency with which most categories tend toward multiple sense is something that perfectly depicts the way they are structured around a prototypical center; the way different "things" can resemble, in several respects, the prototype and, thus, be included in the same category; and how belonging to a given category does not require verification of all "expected" properties; hence members do not need to share a set of common properties (Silva, 2006: 298; our translation).

Geeraerts (1989) postulates that prototypicality is inherently a prototypical notion, since it is not confined to a single fact, a single characteristic or result; instead, it apprehends varied facts, several characteristics or different results and is not necessarily co-extensive. For Geeraerts, the corresponding characteristics or effects of prototypicality, identified in the various psychological and linguistic, but not systematized, studies of prototypes, derive from two essential properties of categorization: non-equality among the items of a category, that is, its distinct degrees of salience and the internal structure of the category in the form of core and periphery, as well as non-discreteness, that is, the flexibility of those items and of that category and the demarcation problems resulting therefrom. Non-equality emerges extensionally at the distinct levels of representativeness among the members of a category and intentionally 
in the agglomeration of family resemblance meanings of the form $A B, B C, C D, D E$ and in resulting overlaps. Non-discreteness also displays two effects: extensionally, fluctuations at the boundary of a category, which reveals the absence of precise boundaries, and intentionally, the definitional restrictions in terms of necessary and sufficient conditions.

The question that arises is the following: Are there any categories that are more prototypically prototypical?

An example enables us to illustrate the question. There are categories that are better candidates for prototypical prototypicality, since they combine all four types of prototypicality effects. For example, fruit, in its proper and non-technical sense, has members that are more representative, such as apple, orange, banana and pear, than other items, such as cucumber, tomato and olive, a structure of overlapping items and, in "family resemblance", fluid boundaries. On this issue, Silva claims that:

The olive is a dubious member, because it lies in an area of fruit and vegetable overlap, and it cannot be defined in terms of "necessary and sufficient conditions". The same is true of the verb deixar [to leave] (cf. our analysis in Silva, 1997, Chapter 2). As for bird (in Portuguese, ave but also pássaro), although it exhibits some specimens that are more representative than some others (cf. the sparrow or the thrush when compared to the penguin or the ostrich) and the cluster of its items is formed according to partial similarities and not according to its common properties (features such as "ability to fly", "feathered" and "winged" are not common to all species, because the penguin and the ostrich cannot fly, and the penguin does not have noticeable feathers, etc.), it is an extensionally discrete category (well-informed speakers know that the bat is not a bird but the penguin is); and this shows that the degree of membership to a category and the degree of representativeness are not necessarily implied. And the color terms are characterized by prototypical effects at the extensional level but not at the intentional level; that is, they are psychologically represented by focal colors (prototypical hues), and the boundaries among them are distinctly fluid, but each color term may be defined in discrete terms and according to properties that are common to all its hues (such as, for red, "a color that is more like that of blood than like that of an unclouded sky, that of grass, that of the sun, that of the..."; cf. Wierzbicka, 1985: 342). Even more: a mathematical concept, such as that of odd numbers, despite being extensional and intentionally discrete, presents degrees of representativeness among its items (odd numbers below 10 are psychologically more salient); this shows that even scientific concepts can be the object of prototypical effects. All this proves the existence of various effects or types of prototypicality, which intersect (and which can be combined in different ways) but that do not imply common determinants of typicality (Silva, 1997: 68-69; our translation).

Another question that arises is: Why are categories formed and organized in terms of prototypicality? Geeraerts (1988a) argues for a psychological and functional explanation:

Can we move beyond the descriptive level and explain why prototypicality exists at all? There are at least four different hypotheses that have been proposed to explain prototypical phenomena. 
Each of these hypotheses has been formulated (or at least hinted at) by Eleanor Rosch herself; this is an indication that the hypotheses might well be complementary rather than mutually contradictory. I will call these four hypotheses the physiological, the referential, the statistical, and the psychological one (Geeraerts, 1988a: 207)

Geeraerts's (1988a) psychological and functional explanation is based on the principle that prototypically structured categories are cognitively more efficient because they have the advantage of flexibility, a characteristic that gives them the possibility of adaptation to the various contexts in which they are used and of creating new entities as rather peripheral members. Moreover, they also exhibit the advantage of stability, which enables the interpretation of new circumstances through existing prototypes, and, therefore, it is not necessary to create or redefine existing categories, which thus maintains the overall structure of the categorical system. Categories are formed and organized in terms of prototypicality, because prototypicality is cognitively useful since it satisfies these two aspects of human cognition. That is why linguistic categories are typically polysemous and flexible, and that is why, in their historical context, the meanings of words are continuous and changeable.

Langacker (1987) believes that schematicity is another process involved in categorization, consisting in generalization or abstraction. For Langacker, the schema is:

(...) an abstract characterization that is fully compatible with all the members of the category it defines (so membership is not a matter of degree); it is an integrated structure that embodies the commonality of its members, which are conceptions of greater specificity and detail that elaborate the schema in contrasting ways. The two modes of categorization are nonetheless inherently related and describable as aspects of a unified phenomenon (Langacker, 1987: 371).

We can say that schema and prototype and categorization by schema as well as categorization by prototype do not complement each other (Taylor, 1995).

In the semantics of a lexical item, whether polysemous or not, there are schematic and specific, prototypical and peripheral meanings or referents. For this reason, its structure takes the form of a network. Langacker (1987: 377-386) refers to the "network model" as the representation model of the structure of categories that combines schemas and prototypes.

In fact, according to Langacker:

(...) a schematic network includes a finite set of nodes, which can be linguistic structures of any sort. Every node is linked to at least one other through a categorizing relationship, of which there are several types: full schematicity (at varying elaborative distances); partial schematicity (with varying degrees of $\mathrm{S} / \mathrm{T}$ discrepancy); or a bidirectional relationship decomposable into component relations of the aforementioned kinds. Each of the nodes and categorizing relationships in the network has a certain degree of cognitive salience, as determined by entrenchment and other factors. 
Within a schematic network, therefore, certain nodes and relationships are far more prominent and important than others, both cognitively and linguistically. In particular, special significance attaches to the nodes that function as the category prototype and as the highest level schema. The prototype is significant because of its developmental priority and notable cognitive salience. As the primary basis for extension, it defines the center of gravity for the category. The highest-order schema is significant, because it embodies the maximal generalization that can be extracted as a characterization of the category membership (Langacker, 1987: 380).

The traditional and limited distinction between semantic information and encyclopedic information is outweighed by the importance of prototypicality, leading dictionaries to include not only the semantic or intentional level of the semantic structure but also its referential or extensional level and to present information on prototypical samples and on the prototypical properties of a word.

In the context of cognitive semantics, we can recognize a unitary view of the lexicon in the notion of prototype.

Some questions are raised about the application of prototype theory to lexical semantics, such as the unclear definition of the concept of category and the problems raised by its extension to the lexical unit. However, it should be noted that, regardless of these issues, prototype theory was a revolution in research on lexical meaning. In fact, in advocating an intersection model, prototype theory enables semantic and non-semantic relationships to function at the same level.

Teixeira (2001: 61) claims that:

The prototype (or the prototypicality effect) is just the tip of the iceberg, which indicates that categorization does not rely on sets of necessary and sufficient conditions but on cognitive associations between a prototypical model and the item to be categorized. This is, as far as we are concerned, the revolutionary essence of cognitive semantics. It is certainly not the only feature that distinguishes prototype theory from classical componential conceptions, but it is, in its apparent (or real?) simplicity, a new way for us to understand the conceptualization-language process (Teixeira, 2001: 61; our translation).

\section{Conclusion}

As a result of research conducted in the various areas of contemporary linguistics, we now have access to in-depth knowledge associated with lexical units, in its oral and written forms, focusing on their internal structure, their inflection and the relationship with words belonging to the same lexical field, their meanings, the range of their classification, their relations with other units within the syntactic domain, their combinatorial possibilities as well as the semantic relationships established with other words. 
After going through a long period of controversy, Semantics has become more and more popular. In this era of transformation, the issue of meaning and reference equated in a general perspective has gained momentum. The conception of meaning is truly complex, considering the multiplicity of theoretical approaches and the variety of disciplinary fields that address this issue. In this context, equating the issues related to meaning requires the stated theoretical frameworks to be delimited, at the moment when we attempt to simplify an object as variable as language.

According to prototype theory, advocated by Cognitive Linguistics, the linguistic categorization usually takes place on the basis of prototypes, and, therefore, linguistic categories have a prototypical structure, based on prototypes.

In the course of the eighties of the twentieth century, there was a context that brought together linguistics, computer science and cognitive psychology, establishing what we currently name cognitive sciences. It is in this context that the conceptions of meaning and of reference, which have engaged scholars for thousands of years, have been re-problematized, thus reopening the debate over these concepts.

Since meanings are not conceptual objects but interpretations, a methodology that is not only non-objectivist or experientialist, as Lakoff (1987) and Johnson (1987) claim, but also hermeneutic, according to Geeraerts (1988b), is imposed to Semantics. In light of the above, the answer to the continuous problem of interpretation (ECO, 2004) is based on the empirical evidence of interpretation of linguistic expressions in the individual, collective and historical experience, in the behavior of the speakers who use them and in the physiology of the human conceptual apparatus. These criteria naturally require the observation of the actual use of linguistic expressions and, henceforth, the importance of quantitative methods based on the corpus (Silva, 2006: 319), which enable the examination of the acts of meaning that the speakers produce, the experiential support that determines them and the whole field of word use.

\section{Bibliographic references}

AbRAntes, Ana Margarida, 2011: Introdução à Semântica, Lisboa: Universidade Católica Editora.

Coleman, Linda, \& Paul Kay, 1981: "Prototype semantics: The English word lie”, Language 57, 26-44.

Eco, Umberto, 2004: Os limites da Interpretação, 2nd ed., São Paulo: Perspectiva.

Fauconnier, Gilles, \& Mark Turner, 2002: The Way We Think: Conceptual Blending and the Mind's Hidden Complexities, New York: Basic Books.

Feltes, Heloísa, 2007: Semântica Cognitiva: Ilhas, pontes e teias, Porto Alegre: Edipucrs. 
Franckel, Jean-Jacques, 2006: "Situation, contexte et valeur référentielle”, Pratiques 129/130, 51-70.

FREGE, Gottlob, 1973: Estudios sobre Semántica, Barcelona: Editorial Ariel.

Geeraerts, Dirk, 1985: Paradigm and Paradox. Explorations into a Paradigmatic Theory of Meaning and its Epistemological Background, Leuven: Leuven University Press.

GeERAerTs, Dirk, 1988a: “Where does prototypicality come from?” in Brygida Rudzka-Ostyn (ed.): Topics in Cognitive Linguistics, Amsterdam: John Benjamins, 207-229.

GeERaerTs, Dirk, 1988b: “On necessary and sufficient conditions”, Journal of Semantics 5, 275-291. Geeraerts, Dirk, 1989: "Prospects and problems of prototype theory”, Linguistics 27, 587-612.

Geeraerts, Dirk, 1995: “Cognitive Linguistics” in Jef Verschueren et al. (eds.): Handbook of Pragmatics, Amsterdam: John Benjamins, 111-116.

Geeraerts, Dirk, 1997: Diachronic Prototype Semantics. A Contribution to Historical Lexicology, Oxford: Oxford University Press.

Johnson, Mark, 1987: The Body in the Mind: The Bodily Basis of Meaning, Imagination and Reason, Chicago: The University of Chicago Press.

KLeIBeR, Georges, 1990: La Sémantique du Prototype. Catégories et sens lexical, Paris: Presses Universitaires de France.

LakofF, George, 1987: Women, Fire, and Dangerous Things. What Categories Reveal about the Mind, Chicago: The University of Chicago Press.

Lakoff, George, \& Mark Johnson, 1980: Metaphors We Live By, Chicago: The University of Chicago Press.

Lakoff, George, \& Mark Johnson, 1999: Philosophy in the Flesh: The Embodied Mind and its Challenge to Western Thought, New York: Basic Books.

Lakoff, George, \& Mark Turner, 1989: More than Cool Reason: A Field Guide to Poetic Metaphor, Chicago: The University of Chicago Press.

LANGACKER, Ronald W., 1987: Foundations of Cognitive Grammar, vol. I: Theoretical Prerequisites, California: Stanford University Press.

LANGACKER, Ronald W., 1990: Concept, Image and Symbol. The Cognitive Basis of Grammar, Berlin / New York: Mouton de Gruyter. 
LANGACKER, Ronald W., 1991: Foundations of Cognitive Grammar, vol. II: Descriptive Application, Stanford: Stanford University Press.

LANGACKER, Ronald W., 1999: Grammar and Conceptualization, Berlin / New York: Mouton de Gruyter. LANGACKER, Ronald W., 2008: Cognitive Grammar. A Basic Introduction, Oxford: Oxford University Press.

Medin, Douglas L., \& Edward E. Smith, 1984: “Concepts and concept formation”, Annual Review of Psychology 35, 113-138.

Mesquita, Pedro António, 1997: "Palavras e coisas: subsídios para a compreensão do Crátilo platónico”, Humanitas 49, 85-102.

Rastier, François, Marc Cavazza e Anne Abeillé, 1994: Sémantique pour l'analyse: de la linguistique à l'informatique, Paris: Masson.

Rodrigues, Alexandra Soares, 2012: Jackendoff e a Arquitetura Paralela Apresentação e discussão de um modelo de linguagem, München: Lincom.

Rosch, Eleanor, 1978: "Principles of categorization" in Eleanor Rosch \& Barbara B. LLoyd (eds.): Cognition and Categorization, Hillsdale, N.J.: Lawrence Erlbaum, 27-48.

Talmy, Leonard, 1983: "How language structures space” in Herbert Pick \& Linda Acredolo (eds.): Spatial Orientation: Theory, Research and Application, New York: Plenum Press, 225-282.

Talmy, Leonard, 1988a: “Force dynamics in language and cognition”, Cognitive Science 12, 49-100.

TALmy, Leonard, 1988b: "The relation of grammar to cognition" in Brygida RudzKa-Ostyn (ed.): Topics in Cognitive Linguistics, Amsterdam: John Benjamins, 165-205.

TALmy, Leonard, 2000: Toward a cognitive semantics, vol. I: Concept structuring systems, Vol. II: Typology and Process in Concept Structuring, Cambridge, Mass.: MIT Press.

Saussure, Ferdinand, 1978: Curso de Linguística Geral, Lisboa: D. Quixote.

SıLva, Augusto Soares, 1997: "A Linguística Cognitiva - uma breve introdução a um novo paradigma da linguística”, Revista Portuguesa de Humanidades, 59-101.

Silva, Augusto Soares, 2006: O mundo dos sentidos em português: Polissemia, semântica e cognição, Coimbra: Almedina.

Sмiтh, Edward E., \& Douglas L. Medin, 1981: Categories and Concepts, Cambridge, Mass.: Harvard University Press. 
TAyLoR, John R., 1995: Linguistic Categorization. Prototypes in Linguistic Theory, 2nd ed., Oxford: Clarendon Press (1st ed., 1989).

TelXeIRA, José, 2001: A Verbalização do Espaço: Modelos Mentais de frente/trás, Braga: Universidade do Minho, Centro de Estudos Humanísticos.

Traugott, Elizabeth Closs, \& Richard B. Dasher, 2002: Regularity in Semantic Change, Cambridge: Cambridge University Press.

Wierzbicka, Anna, 1985: Lexicography and Conceptual Analysis, Ann Arbor: Karoma Publishers.

Wittgenstein, Ludwig, 1979: Investigações Filosóficas, 2nd ed., transl. José Carlos Bruni, São Paulo: Abril Cultural. 